\title{
Integrated Approach of Naturopathy And Physiotherapy in Patient With Post Operative Hip Arthroplasty-A Case Report
}

\author{
Dr.Vijayaraghavan $\mathrm{N}^{1}$, Dr.Chidananda Murthy $\mathrm{B} \mathrm{T}^{2}$, Anto Princy ${ }^{3}$ \\ ${ }^{1}$ Assistant Professor, Department of First Aid, Emergency Medicine and Physiotherapy, JSS Institute of \\ Naturopathy and Yogic sciences, Coimbatore, TamilNadu \\ ${ }^{2}$ Principal cum CMO, JSS Institute of Naturopathy and Yogic Sciences, Coimbatore, TamilNadu \\ ${ }^{3}$ Final Year, Resident, Naturopathy \& Yoga, JSS Institute of Naturopathy and Yogic Sciences, Coimbatore,
} TamilNadu,

\begin{abstract}
Avascular Necrosis (AVN) of the bone, aseptic necrosis and ischemic bone necrosis, is a relatively common disease characterized by death of the cellular elements of bone and marrow due to the interruption of the blood supply. Patients tend to suffer from post surgical pain, limitataion of motion with stupping gait along with aggravating of pain, numbness \& spasm in gluteal region. This condition has a number of charactertics clinical and radiographic signs that differentiate it from other osteonecrotic conditions. 'Mitchell's GRADE A' with marrow edema in head \& neck regions of femur being the first charactertics of diagnostic feature. This is a case report of single post surgical issues with history of severe pain and difficulty in walking.
\end{abstract}

\section{Introduction}

Avascular Necrosis of the bone, also known as Osteonecrosis, aseptic necrosis and ischemic bone necrosis, is a relatively common disease characterized by death of the cellular elements of bone and marrow due to interruption of the blood supply. ${ }^{[1]}$ Most individuals who develop AVN are between ages of 20 and 50 years. The hip (femoral head) is the most commonly affected sites for clinically significant avascular necrosis.Osteonecrosis of femoral head is a devastating disease which often leads to the destruction of the hip. It is employed only in early stages of arthritis and its results are still of controversial efficacy and most of patients ultimately require total hip arthroplasty. ${ }^{[2,3]}$ Patients present with severe pain, gluteal region spasm and numbness with difficulty in walking. Recognition of these condition signs are important in order to make the post operative care and prevent possible complications.

\section{Case Report}

We report a case of 65 year old male with surgical procedure [Uncemented right \& left total hip replacement] for arthritis of both hips secondary to avascular necrosis of femur head. He also provided a history of multiple surgical procedure for spine like lumbar discecteomy, arthritis of knee earlier, including necrosis of both femoral head's with marrow edema in head \& neck regions of left femur and acetabulum. On Clinical examination, the patient demonstrated dysmorphic features with short range of movement and proportionally shorter right limbs. He had a large dense mass of bone with limitation of movement in the back of the spine. MRI of spine investigation revealed arthritis of both hips secondary to avascular necrosis of femur head and S/P L4-L5 Microdiscectomy bilateral core decompression. Lower extremities shows dryness of skin and swelling of both legs.The patient was subjected to special tests like Thomas test shows negative; Trendelenberg test couldn't be done due to severe of pain, telescopy becomes negative and others are like nelation, shoemaker's line normal. Femur radiographs showed suggestive of avascular necrosis of both femoral heads [MITCHELL'S GRADE A] as described with marrow edema in head \& neck regions of left femur and left acetabulum (Fig 1A).The(Fig 1B)Both femorals heads shows osteonecrotic changes.
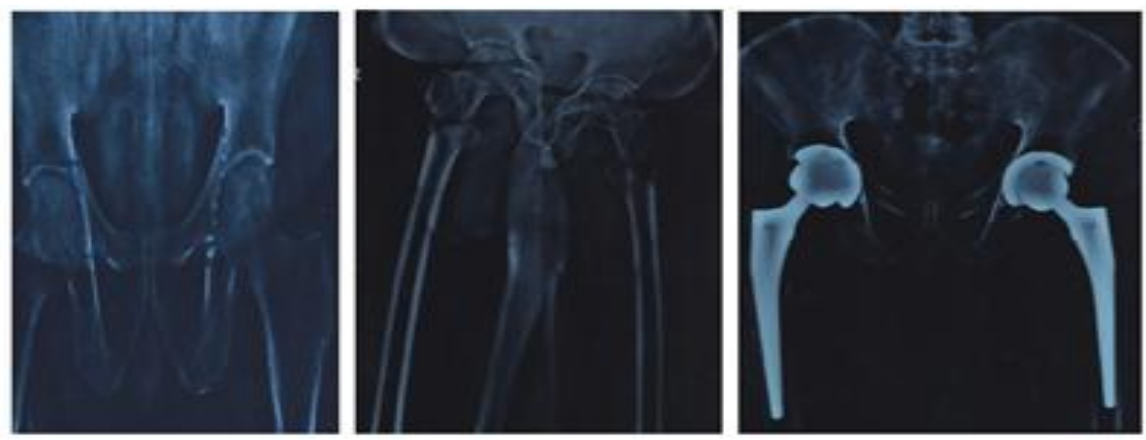

Fig 1: 1A- Avascular necrosis of both femoral head with Marrow edema in head \& neck regions of left femu and acetabulum, 1B- shows femoral heads osteonecrotic changes in both femurs. 
Fig 2. Post Surgical X-rays shows artificial uncemented $32 \mathrm{~mm}$ biolox delta ceramic femoral head $(+5)$ size was Implanted.

\section{Discussion}

Osteonecrosis of the hip is characterized pathophysiologically by ischemia of bone marrow and eventual death of trabecullar bone. The key of successful management of hip osteonecrosis is early treatment, prior to onset of subchondral fracture and cartilage damage. ${ }^{[4-6]}$ Approximately, $5 \%-18 \%$ of all hip arthroplasties are completed on patients with a primary diagnosis. ${ }^{[7,8]}$ During diagnostic classification of osteonecrosistic medial thigh or groin pain with limitation of hip motion in patient's less than 50 years of age should raise the suspicion of osteonecrosis. Patients usually present with slow onset, insidious groin pain that may be unilateral or bilateral. Symptoms are generally amplified with weight bearing and relieving by rest. The pain may also be in gluteal region, kness, or anterior and lateral thigh. Range of motion becomes limited, particularly hip abduction and internal rotation and logrolling elicits pain. ${ }^{[9]}$ Early stages of this disease can be often asympotatmatic, and some patients present after articular surface collapse has already occurred. Hip prognosis can be significantly improved with early diagnosis, before articular collapse.

Other potential etiologies for osteonecrosis include childhood history of slipped capital femoral epiphysis (SCFE), deep sea diving or other hyperbaric conditions, SLE and other connective tissue disorders, fat embolus syndrome, gout and metabolic bone disease. ${ }^{[10,11]}$ The diagnosis is primarily based on the afore mentioned radiographic features (Pre \& Post Surgery).Fig.2. However, a post operative rehabilitation [Physiotherapy and Naturopathy] remains the gold standard treatment with longer duration of passive movement for duration of 15-20 minutes daily. Majority of the soft tissue heals in the first 12 weeks after surgery with minimal passive movements for total hip and legs (Table.1.1.1).Specific treatment options with supportive measures, prevention and management consisting the most important aspects of clinical care for the pain and disability from the arthritis influencing the quality of life and daily activities.

\section{Conclusion}

Osteonecrosis is a pathology commonly seen in adults, in which collapse of femoral head and early onset of osteoarthritis may eventually necessiatate hip arthroplasty when non-operative measures. Basic science research to understand the pathophysiology and to develop therapies that can be translated to clinical application has progressed rapidly.Similarily, modern technologies improvements in surgical treatment methods have also improved outcomes over the past two decades and will continue to help the patient recover from this functionally debilitating joint disease. The importance of recognition of these features in the diagnosis and prevention of future complications is stressed in this case report with integrated approach.

\section{References}

[1]. Tofferi JK, Gilliland W. Avascular Necrosis. Medscape 012.http://emedicine.medscape.com/article/333364- overview [Accessed on Sep 23, 2013].

[2]. Mont MA, Hungerford DS. Non-traumatic avascular necrosis of the femoral head. J Bone Joint Surg Am 1995, 77(3):459-474.

[3]. Mont MA, Jones LC, Hungerford DS. Non-traumatic osteonecrosis of head: ten years later. J Bone Joint Surg Am 2006; 88(5):1117-32.

[4]. Meyers MH. Osteonecrosis of the femoral head: pathogenesis and long term results of treatment.Clin Orthop 1988; 231:57-61.

[5]. Stulberg MN, Davis AW, Bauer TW, Levine M, Easley K. Osteonecrosis of the femoral head: a prospective randomized treatment Protocol. Clin Orthop 1991; 268:140-151.

[6]. Steinberg ME, Bands RE, Parry S, Hoffman E, Chan T, Hartman KM. Does lesion size affect the outcome in avascular necrosis? Clin Orthop 1999; 367: 262-271.

[7]. Mankin HJ. Nontraumatic necrosis of bone (osteonecrosis). N Engl J Med 1992; 326: 1473-1479.

[8]. Vail TP, Covington DB. The incidence of osteonecrosis. In Osteonecrosis: Etiology, Diagnosis, Treatment. Rosemont, IL: American Academy of Orthopaedic surgeons; 1997:43-49.

[9]. Steinberg ME. Avascular necrosis: diagnosis, staging, and management. J Musculoskel Med 1997; 14: 13-25.

[10]. Larson AN, McIntosh AL, Trousdale RT, Lewallen DG. Avascular necrosis most common indication for hip arthroplasty in patients with slipped capital femoral epiphysis. J Pediatr Orthtop 2010; 30: 767-773.

[11]. Luedtke LM, Flynn JM, Pill SG. A review of avascular necrosis in developmental dysplasia of the hip and contemporary efforts at Prevention, Univ Penn Orthop J 2000; 13: 22-28. 
TABLE 1.1.1 Naturopathic and Physiotherapic intervention

\begin{tabular}{|c|c|c|c|c|c|}
\hline DAY & $\begin{array}{c}\text { Morning Rx- } \\
\text { NaturopathyRx+Diet }\end{array}$ & Evening Rx & DAY & Morning Rx & Evening $\mathbf{R x}$ \\
\hline 1. & Diet with Ragi & PM with ST-Duration-10Min & 12. & Boiled Diet & Walking with ST \\
\hline 2. & Steam Bath+BD & PM with ST-Duration-10Min & 13. & $\begin{array}{l}\text { Oil application } \\
+ \text { IR-10 Min }\end{array}$ & Walking with ST \\
\hline 3. & Boiled Diet & PM with ST-Duration-10Min & 14. & Boiled Diet & $\begin{array}{l}\text { PM with ST-10M,BS } \\
-5\end{array}$ \\
\hline 4. & Boiled Diet & PM with ST-Duration-10Min & 15. & Sauna Bath & Walking with ST \\
\hline 5. & PM to Legs & PM with ST-Duration-10Min & 16. & Boiled Diet & Walking with ST \\
\hline 6. & Boiled Diet & PM with ST,WA with ST-15M & 17. & $\begin{array}{ll}\text { NIB } & \text { with } \\
\text { Epsom } & \end{array}$ & $\begin{array}{l}\text { PBS-10min with } \\
\text { walking }\end{array}$ \\
\hline 7. & Boiled Diet & PM with ST,WA with ST-15M & 18 & Diet with Ragi & $\begin{array}{l}\text { Quadriceps ST with } \\
\text { WA }\end{array}$ \\
\hline 8. & Diet with Ragi & PM with ST,WA with ST-15M & 19. & Diet with Ragi & $\begin{array}{l}\text { Quadriceps ST with } \\
\text { WA }\end{array}$ \\
\hline 9. & $\begin{array}{l}\text { Oil application + IR-10 } \\
\text { Min }\end{array}$ & PM with ST,WA with ST-15M & 20. & $\begin{array}{l}\text { Boiled } \\
\text { Diet[Rice with } \\
\text { Veg.Salads }\end{array}$ & $\begin{array}{l}\text { PM with ST-15- } \\
\text { 20Min }\end{array}$ \\
\hline 10. & Boiled Diet & PM with ST,WA with ST-15M & 21. & Boiled Diet & $\begin{array}{l}\text { Walking aids-15- } \\
\text { 20Min }\end{array}$ \\
\hline 11. & Boiled Diet & PM with ST,WA with ST-15M & 22. & Boiled Diet & $\begin{array}{l}\text { Adductors } \\
\text { Strength(Chair } \\
\text { Strengthening } \\
\text { Exercises) -10- } \\
\text { 20Min. Walking } \\
\text { pattern-20Minutes }\end{array}$ \\
\hline
\end{tabular}

\section{Naturopathic Intervention}

PM-Partial Message, IR-Infrared Lamp/Light, BOILED DIET- Chapatti with Vegetable Salads, BD-Boiled Diet

Physiotherapy Intervention - PM-Passive Movements, ST-Sustained stretching, AM- Active Movements, WPWalking Pattern, PBS- Polar band Stretching. 